\title{
Main performance analysis of kitchen waste gasification in a small-power horizontal plasma jet reactor
}

\author{
Huixin $\mathrm{Li}^{\mathrm{a}, \mathrm{b}}$, Teng $\mathrm{Li}^{\mathrm{a},{ }^{*}, \text { Xiaolin Wei }}{ }^{\mathrm{a}, \mathrm{b}}$ \\ a State Key Laboratory of High Temperature Gas Dynamics, Institute of Mechanics, Chinese Academy of Sciences, No. 15 Beisihuanxi Road, Beijing, 100190, \\ China \\ ${ }^{\mathrm{b}}$ School of Engineering Science, University of Chinese Academy of Sciences, 19 A Yuquan Road, Beijing, 100049, China
}

\section{A R T I C L E I N F O}

\section{Article history:}

Received 17 September 2018

Received in revised form 21 February 2019

Accepted 26 February 2019

Available online 6 March 2019

\section{Keywords:}

Gasification

Plasma torch

Kitchen waste

Syngas

Graphitization

\begin{abstract}
A B S T R A C T
Plasma gasification technology has been demonstrated in recent studies as one of the most effective and environmentally friendly methods for solid waste treatment, which could be attractive for resource and energy recovery from kitchen waste. This study focuses on the effects of plasma gasification of kitchen waste replaced by $85 \%$ flour and 15\% vegetables (Mass Fraction), including dimensionless operation parameters, ER (equivalence ratio), SFR (steam to feedstock ratio) and the gasification efficiency. The Horizontal plasma jet reactor is employed in the experiments. It is found that the influence of the equivalence ratio on syngas can be divided into positive and negative parts. And the steam injection is conducive to improving the yield of syngas, which mainly results from the heterogeneous water gas shift reaction. The optimal experimental parameters can be obtained at $\mathrm{ER}=0.095$ and $\mathrm{SFR}=0.084$. Besides, the maximum first and second efficiency of plasma gasification during these cases occurs in SFB $=0.084$, accounting for $28.2 \%$ and $23.0 \%$, respectively, which needs to study further to get improvement. The XRD and Raman spectra are applied to characterize the residual char, which may illustrate that the degree of graphitization is competing with a high yield of syngas during plasma gasification.
\end{abstract}

() 2019 Energy Institute. Published by Elsevier Ltd. All rights reserved.

\section{Introduction}

With the increase of population, consumerism has resulted in a rise in the quantities of Municipal Solid Waste (MSW) [1], which is a crucial issue both in developed and developing countries. And the kitchen waste, one of the MSW, has obtained broad concerns owing to its intimate relevance with individuals' profits. Table 1 shows that the total kitchen waste generated in a year among different regions.

It is obvious to see that the treatment of kitchen waste has become one of the urgent problems in our time. Some methods for utilizing biomass waste including kitchen waste are fermentation to make a liquid fuel (e.g. alcohol and carbonization) or to make a solid fuel [5]. Concurrently, various thermal processes, including incineration, pyrolysis and gasification, have been proposed for treating solid waste, such as agricultural waste [6], waste polypropylene [7] and kitchen waste. The thermal processes are of great potential as a renewable and commercial application. Besides, among these methods of waste disposal, gasification is one of the promising technologies [8,9].

Plasma is an ionized gas resulting from an electrical discharge, which is classified as high-temperature plasma and low-temperature plasma. Further, the latter can be divided into thermal plasma and non-thermal plasma. As for the thermal plasma used in waste treatment, it can be generated by a direct current (DC) or an alternating current (AC) electrical discharge or a radio frequency (RF) induction or microwave (MW) discharge [10,11]. In a DC arc plasma jet, the temperature in the core of the plasma jet could reach and keep over $30000 \mathrm{~K}$, whereas in the marginal zone, the temperature decrease rapidly and the average operating temperature can be high as $5000 \mathrm{~K}$. Thus, DC arc plasma torch is available for our gasification experiment because of its stable arcs and high temperature.

Plasma gasification is a technologically advanced and environmentally friendly process of disposing wastes and converting them to commercially useable products. During the process, due to the extremely high temperature generated by plasma torch, the input kitchen wastes are decomposed into simple elements in an oxidant starved environment [12,13]. Simultaneously, the high temperature decomposes

\footnotetext{
* Corresponding author.

E-mail address: liteng@imech.ac.cn (T. Li).
} 
Table 1

Total kitchen waste generated in a year among three regions.

\begin{tabular}{llll}
\hline Region & Thousands of Tons & Year & Ref. \\
\hline P. R. China & 58000 & 2010 & {$[2]$} \\
EU (28 countries) & 52000 & 2010 & {$[3]$} \\
US & 34290 & 2009 & {$[4]$} \\
\hline
\end{tabular}

toxic compounds to harmless chemical molecules, which is exactly an enormous advantage compared with the traditional gasification [14]. With the increased cost of environmental management and environmental protection, plasma gasification could be attractive for resource and energy recovery from kitchen waste.

Tang et al. [15] reported the influence of plasma power, feed rate, particle size during the pyrolysis of polypropylene in a nitrogen plasma reactor. Li et al. [16] and Zhang et al. [17] used $30 \mathrm{~kW}$ DC arc to treat chemical and hazardous wastes, explaining the formation mechanism of vitrified slag. As for modeling, Mountouris et al. [12,18] firstly developed the GasifEq equilibrium thermodynamic model which described thoroughly the plasma gasification process. Through Aspen Plus process model, Zhang et al. [9,19] systematically obtained the gasification parameters and efficiency in term of MSW gasification melting process under different operation conditions, while Favas et al. [20] got the main operating variables with respect to biomass gasifier performance. The different types of feedstocks were taken into account by Janajreh et al. [21] using Aspen Plus model, during which the results of plasma gasification shows that high gasification efficiency is achievable by using both tire waste material and coal. Overall, the former studies mentioned above pay much attention to the operation parameters, such as the equivalence ratio (ER), the steam to feedstock ratio (SFR) and the cold gas efficiency (CGE), by equilibrium thermodynamic model analysis rather than gasification experiments. Therefore, it is necessary to obtain optimal ER and SFR through a number of DC plasma gasification experiments, which is instructive for the chemical equilibrium model and future application of plasma gasification technology.

In this study, the DC plasma torch was employed to gasify the kitchen waste, in which we have investigated the performances of gasification. The kitchen waste was dried and milled into powder before getting into the gasification chamber and the plasma gasification of air and steam injection were studied, respectively. The purpose of this study is to get some guide suggestions and optimized operation parameters to design a system of larger power plasma gasification.

\section{Experiment devices}

The experimental system contains plasma torch, gasification chamber, Fourier Transform Infrared (FTIR) spectroscopic gas analyzer, screw feeder and plasma torch power supply. Fig. 1 indicates the sketch of the experimental system. The maximum power output from this plasma torch with $\mathrm{N}_{2}$ as working gas is about $1 \mathrm{~kW}$. The length of the plasma torch is $150 \mathrm{~mm}$ and the power supply parameters (working voltage and current of plasma torch) are measured by voltmeter and amperemeter, respectively. The length and inner diameter of the gasification chamber are $95 \mathrm{~mm}$ and $30 \mathrm{~mm}$ and the observation window is located in the middle of the chamber. In front of the chamber, two nozzles are installed as inlets of kitchen waste powder and air. The screw feeder is of small mass flow rate which is $1.58 \times 10^{-4} \mathrm{~kg} / \mathrm{s}$. The mass flow controllers (Seven Stars D07 Series) are employed to control the flow rate of air and nitrogen. In the outlet of the chamber, the gasification products are directly collected and detected by FTIR spectroscopic gas analyzer (Gasmet DX-4000), while hydrogen is detected by Hydrogen Analyzer (QRD-1102C)using the thermal conductivity method. During the process of the experiments, asbestos rubber washer is applied for the seal among all the parts. Figs. 2 and 3 are the physical plasma torch and 3D sketch of gasification chamber.

In the experimental study on the influence of steam injection, copper tube wrapped with an electric tracing band is employed to vaporize the water to form steam. Fig. 4 shows the sketch of the steam producer. In order to control the mass flow rate of steam, a stepping motor is applied to pump the water into the sealed tube. Besides, the pipeline transporting air in Fig. 1 is replaced by the copper tube. Concurrently, copper tube fitting is directly employed to connect the copper tube with gasification chamber so that it can decrease the effects on condensation of steam.

Generally, the kitchen waste is of pretty high moisture content, about 70\%-80\% [22], which is detrimental to energy utilization during plasma gasification. Therefore, the kitchen waste in the experiments is dried to $12.3 \%$. In addition, during the experiment, the kitchen waste was substituted by $85 \%$ flour and $15 \%$ vegetables (Mass Fraction). The size of the powder particles is lower than $0.178 \mathrm{~mm}$. The proximate and ultimate analyses of the substitution powder are given in Table 2.

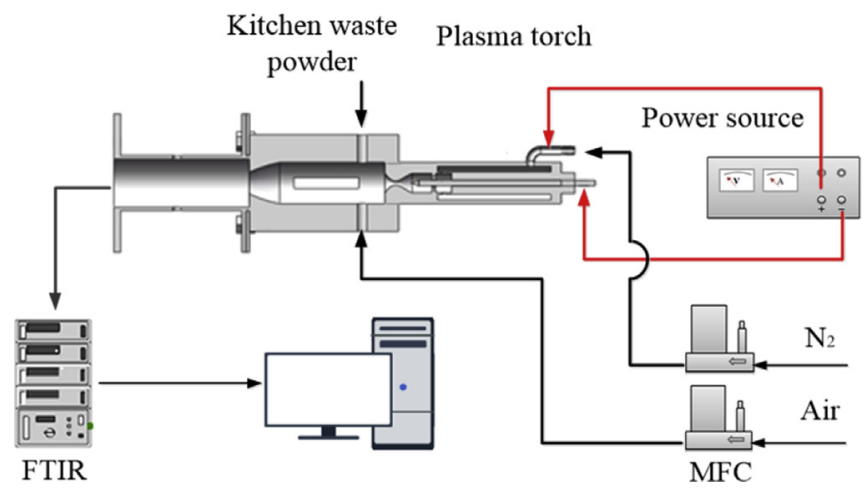

Fig. 1. The sketch of the experimental system. 


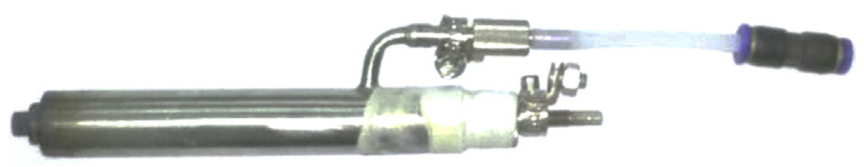

Fig. 2. The physical picture of $1 \mathrm{~kW}$ plasma torch.

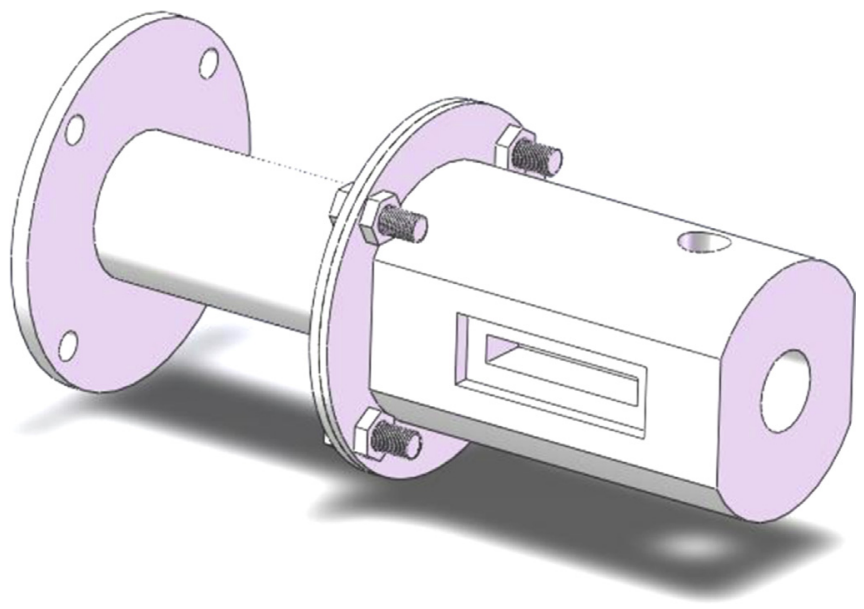

Fig. 3. The 3D sketch of the gasification chamber.

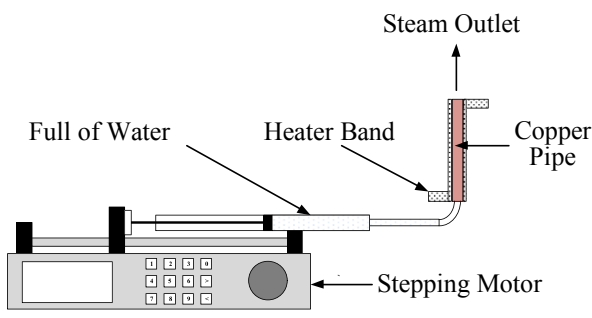

Fig. 4. The sketch of the steam producer.

Fig. 5 indicates that the variation of plasma torch power under different nitrogen mass flow rate. The higher the current is, the larger the stable flow rate range of plasma jet is generated. But the higher current is detrimental to the life of the anode and cathode. Besides, the plasma jet formed in small current is short and narrow, which is of pretty small energy density to gasify better. During all experiments, the red star point in Fig. 5 is employed and the plasma power is about $852 \mathrm{~W}$ (nitrogen mass flow rate is $1.5 \mathrm{~L} / \mathrm{min}$ ) to guarantee the plasma torch can generate the same temperature and velocity field in the gasification chamber. Through this way, it is hardly necessary to consider the mass flow rate effects of working gas on the gasification process. The working gas of the plasma torch is nitrogen. Compared with other working gas, such as air or water, the advantages of nitrogen are that the anode and cathode are not apt to be oxidized by nitrogen plasma. As to argon, although plasma arc is apt to be obtained, the length of the plasma jet is too short, which means the energy density is not large and the gasification effects would be worse.

\section{Results and discussion}

The experiment is conducted with the variation of equivalence ratio and steam to feedstock ratio to study the optimal features of plasma gasification with the power of $1 \mathrm{~kW}$. Equally important, we also use XRD and Raman spectra to characterize the residual to reflect the process of plasma gasification.

\subsection{Effect of equivalence ratio (ER)}

Equivalence Ratio is defined as the ratio of the amount of air actually supplied to the gasifier and the stoichiometric amount of air.

$E R=\frac{\left(\frac{\dot{m}_{\text {air }}}{\dot{m}_{\text {feedstock }}}\right)}{\left(\frac{\dot{m}_{\text {air }}}{\dot{m}_{\text {feedstock }}}\right)_{\text {stoic }}}$

in which $\dot{m}_{\text {air }}$ and $\dot{m}_{\text {feedstock }}$ denote the mass flow rates of the air supplied and the feedstock, respectively. 
Table 2

Ultimate and Proximate analyses of kitchen waste powder.

\begin{tabular}{ll}
\hline Ultimate analyses (\%) & \\
Carbon & 40.03 \\
Hydrogen & 6.88 \\
Nitrogen & 1.99 \\
Oxygen & 47.59 \\
Sulfur & $<0.01$ \\
LHV (MJ/kg) & 15.64 \\
Proximate analyses (\%) & \\
Moisture content & 12.3 \\
Ash & 0.55 \\
Volatile matter & 87.15 \\
Fixed carbon & $<0.01$ \\
\hline
\end{tabular}

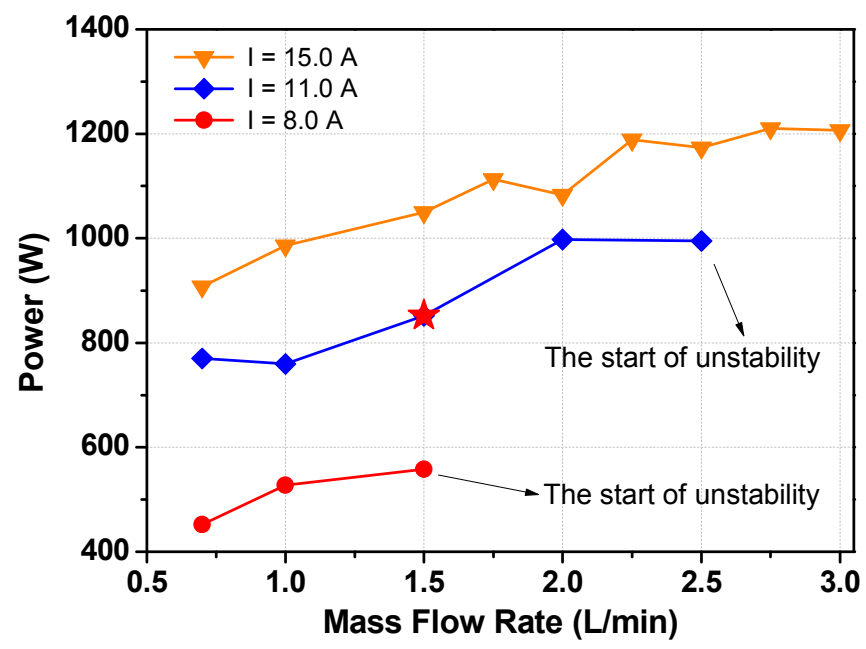

Fig. 5. Variation of the plasma torch power with different nitrogen mass flow rates.

In the plasma gasification process, due to sensible heat supplied by thermal plasma, the ER value is much lower (0.04-0.10) than that of conventional gasifiers (around 0.3) [9], thus, ER was varied from 0.032 to 0.172 during the experiments, showed in Table 3.

It can be observed from Fig. 6 that when ER rises, the concentration of $\mathrm{CO}$ and $\mathrm{H}_{2}$ is of a trend of increase followed by a decrease, in which the maximum values of $\mathrm{CO}$ and $\mathrm{H}_{2}$ occur in $\mathrm{ER}=0.095$ and $\mathrm{ER}=0.130$, respectively. And the trend of $\mathrm{CO}$ concentration is parallel to the literature [9], whose largest point emerges in $\mathrm{ER}=0.065$. The rise in ER also means that more air is introduced in the process, which provides more chemical heat by combustion for gasification. While the decline is induced by the increase of oxygen concentration, in which CO is consumed and subsequently produces novel compounds $\mathrm{CO}_{2}$. Thus, the amount of $\mathrm{CO}_{2}$ ascends when the ER is larger than 0.130 . Concurrently, Fig. 6 demonstrates that the concentration of $\mathrm{CH}_{4}$ nearly keeps stable, while the content of light hydrocarbon decreases after a tendency of rising, with the turning point occurring in ER $=0.072$.

Theoretically, the ER has two contradictory effects upon syngas yield [9]. The positive fact is that higher ER can provide more chemical heat by combustion for gasification, which is conducive to syngas yield and LHV value. However, higher ER also means more combustion happens in the reactor, which will consume some $\mathrm{CO}$ and $\mathrm{H}_{2}$. As a result, the concentrations of $\mathrm{CO}$ and $\mathrm{H}_{2}$ decrease with the increase of ER. Additionally, the increasing $\mathrm{N}_{2}$ introduced into the reactor dilutes the content of combustible gases. As cited above, in Fig. 6 , when the ER is lower than 0.095, ER has a positive influence on plasma gasification. Therefore, the $\mathrm{CO}$ and $\mathrm{H}_{2}$ are of a tendency of rising. While the ER is larger than 0.095 , meaning that more air is introduced in the process, the negative aspect is dominating, which leads to more combustion of combustible gases. Consequently, the content of $\mathrm{CO}_{2}$ rises but the concentration of $\mathrm{CO}$ is adverse.

\subsection{Effect of steam to feedstock ratio (SFR)}

Adding steam is conducive to the plasma gasification during the process [9,15,19]. The high-temperature steam is conducive to promoting the yield of $\mathrm{H}_{2}$ significantly (Table 4). Simultaneously, the steam to feedstock ratio (SFR) [23] is defined as the steam mass flow rate divided by the feedstock mass flow rate:

Table 3

Operation parameters for ER in the experiment.

\begin{tabular}{llllll}
\hline Case & 1 & 2 & 3 & 4 & 5 \\
\hline ER & 0.036 & 0.072 & 0.095 & 0.130 & 0.163
\end{tabular}




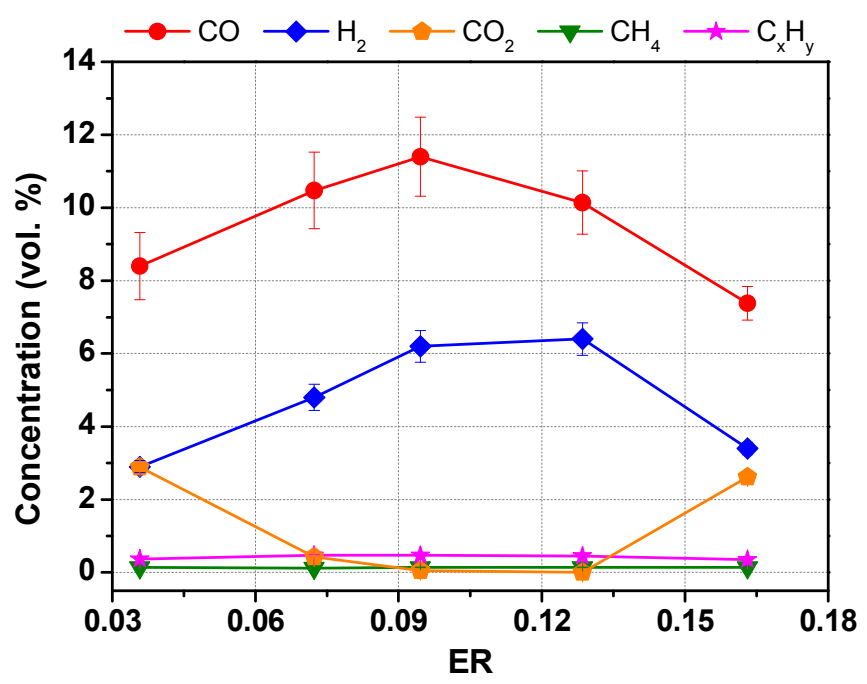

Fig. 6. Effects of the ER on syngas compositions.

$S F R=\frac{\dot{m}_{\text {steam }}}{\dot{m}_{\text {feedstock }}}$

Fig. 7 illustrates that the mole fraction of $\mathrm{CO}$ and $\mathrm{H}_{2}$ are of a rise followed by a trend of decline, in which the maximum values of $\mathrm{CO}$ and $\mathrm{H}_{2}$ emerge in SFR $=0.084$ and SFR $=0.063$, respectively. Compared with Fig. 6 , it is clear to see that steam is beneficial to improving the contents of $\mathrm{CO}$ and $\mathrm{H}_{2}$ during the gasification. This is explained by the fact that the experimental feedstock contains a large mass fraction of fixed carbon and the plasma torch supplies high temperature, it is possible that the increase of $\mathrm{CO}$ and $\mathrm{H}_{2}$ concentration with steam feeding is mainly due to the reactions:

$\mathrm{C}+\mathrm{H}_{2} \mathrm{O}=\mathrm{H}_{2}+\mathrm{CO}$

$\mathrm{C}_{\mathrm{n}} \mathrm{H}_{\mathrm{m}}+\mathrm{mCO}_{2}=2 \mathrm{mCO}+\mathrm{n} / 2 \mathrm{H}_{2}$

where $\mathrm{C}_{\mathrm{n}} \mathrm{H}_{\mathrm{m}}$ stands for tar. There is no doubt that as for the feedstock in experiments, Reaction (3) plays an indispensable role and high temperature gives priority to the Reaction (4) [24] during the gasification with steam, which helps convert carbon residue and tar into content of $\mathrm{H}_{2}$ and $\mathrm{CO}$. Especially when steam supplied increasingly, from case 1 to case 4, as expected, excess steam can also lead to the promotion that the water-gas shift reaction and steam reforming of tar become much more intensive [20], as follow:

$\mathrm{C}_{\mathrm{m}} \mathrm{H}_{\mathrm{n}}+\mathrm{aH}_{2} \mathrm{O}=\mathrm{bCO}+\mathrm{cH}_{2}+\mathrm{dC}_{\mathrm{x}} \mathrm{H}_{\mathrm{y}}$

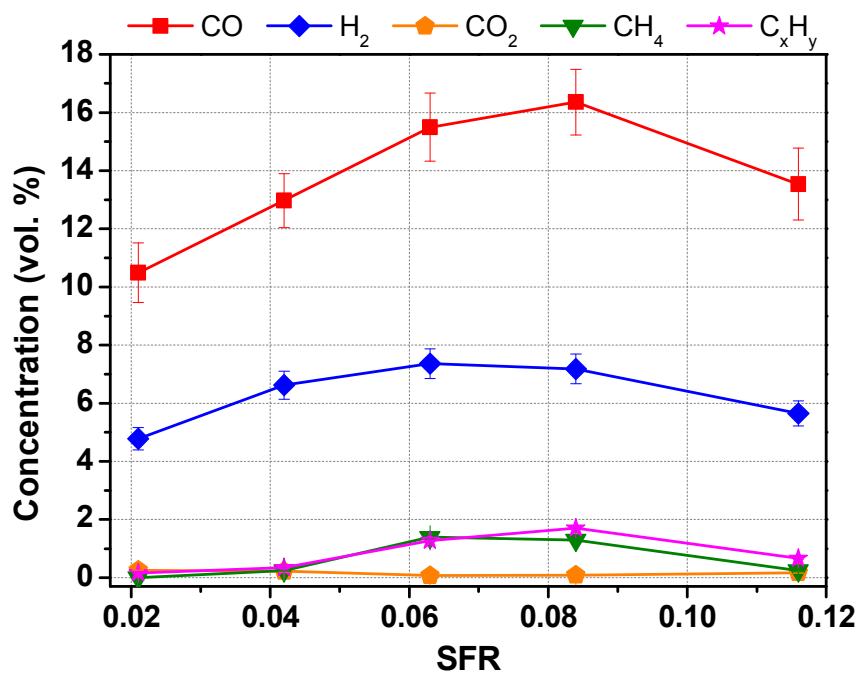

Fig. 7. Effects of SFR on syngas compositions. 
$\mathrm{CO}+\mathrm{H}_{2} \mathrm{O}=\mathrm{CO}_{2}+\mathrm{H}_{2}$

Thus, the content of light hydrocarbons $\left(\mathrm{C}_{\mathrm{x}} \mathrm{Y}_{\mathrm{y}}\right)$ is increased through the Reaction (5). Besides, it is possible that $\mathrm{CO}_{2}$ from Reaction (4) is reduced to the $\mathrm{CO}$ through reaction $\left(\mathrm{C}+\mathrm{CO}_{2}=2 \mathrm{CO}\right)$, which is conducive to giving a high increase rate of $\mathrm{CO}$. However, in case 5 , excess steam gives rise to the consequence that the temperature in the gasification chamber may have a decrease, which is detrimental to gasification. Therefore, the contents of the syngas composition begin to decline.

\subsection{Efficiency based on the first and second thermodynamic laws}

The cold gas efficiency (CGE) is a standard criterion frequently quoted to express the energy efficiency of a gasification process. Thus, the first thermodynamic law efficiency, namely hot efficiency, is the ratio between the energy of the synthesis gas and total energy, as follow:

$\eta=\frac{\dot{m}_{\text {syngas }} \cdot \mathrm{LHV}_{\text {syngas }}}{\dot{m}_{\text {feedstock }} \cdot \mathrm{LHV}_{\text {feedstock }}+P_{\text {electricity }}} \times 100 \%$

where $\dot{m}_{\text {syngas }}$ and $\dot{m}_{\text {feedstock }}$ stand for the mass flow rates of the syngas and the feedstock, respectively, while LHV $V_{\text {syngas }}$ and LHV feedstock are their lower heating values on a mass basis. And $P_{\text {electricity }}$ stands for the total electric power, including power used to heat the steam and plasma power. As for air gasification, the $P_{\text {electricity }}$ is equal to the plasma power.

Concurrently, the second thermodynamic law efficiency, namely exergy efficiency, is employed to evaluate the useful work of the system. Furthermore, the exergy efficiency based only on the chemical exergy of the produced syngas is calculated by Eq. (8) [17], which is similar to the cold gas gasification:

$\varepsilon=\frac{\dot{m}_{\text {syngas }} \cdot E x_{\text {syngas }}}{\dot{m}_{\text {feedstock }} \cdot E x_{\text {feedstock }}+P_{\text {electricity }}} \times 100 \%$

where $E x_{\text {syngas }}$ and $E x_{\text {feedstock }}$ represent the chemical exergy of the produced syngas and feedstock, respectively. The chemical exergy is obtained from the exergy analysis of solid fuel gasification [25], as follow:

$E x_{\text {feedstock }}=\frac{1.044+0.0160 \mathrm{H} / \mathrm{C}-0.34930 / \mathrm{C}[1+0.0531 \mathrm{H} / \mathrm{C}]+0.0493 \mathrm{~N} / \mathrm{C}}{1-0.41240 / \mathrm{C}}$

The results of efficiency based on the first and second thermodynamic laws are shown in Fig. 8. Here, the efficiency varies from about 7\% to about $28.2 \%$. Besides, the energy efficiency of air gasification is obviously lower than that of steam gasification. The tendency of efficiency is similar to that of the concentration of syngas. But it is clear to see that during this $1 \mathrm{~kW}$ plasma gasification, the efficiency is pretty low, which may attribute to three main reasons: the structure of gasification chamber, the stability of plasma torch and the heat loss of the system. In a small-scale system, the gasification is in the horizon plasma jet reactor and small jet, in which the interface between jet and feedstock is narrow. Therefore, residual carbon emerges in the reactor. The second reason is the stability of the plasma torch, which can affect the power of the plasma torch that is crucial to gasification. As to the heat loss of the system, including heat dissipation and tar formation, Ref [19] reports it is approximately $2-5 \%$ of total energy. And the first two reasons are significant in our experimental devices.

\subsection{Residual char characteristics}

The X-ray intensity curves of raw material and the char residue obtained from the plasma gasification are shown in Fig. 9. CA stands for the residual char from plasma gasification of air at $\mathrm{ER}=0.095$, while $\mathrm{CS}$ represent for the residual char from plasma gasification of steam at $\mathrm{SFR}=0.084$. The X-ray intensity curve of raw material presents three peaks in low angle region $\left(2 \theta=5-35^{\circ}\right)$, in which the first two peaks $\left(2 \theta=15-20^{\circ}\right)$ stands for $\gamma$ peak and region about $23.5^{\circ}$ may represent for 002 peak, respectively. The $\gamma$ peak almost certainly stands for aliphatic chains. And the 002 peak, which has also been observed by many other researchers is accepted as standing for the carbon microcrystalline [26-28]. After plasma gasification, as shown in Fig. 9b and c, the $\gamma$ band almost disappeared and the intensity of (002) band decreases, emerging in $2 \theta=25^{\circ}$. The presented results illustrate that most aliphatic chains are decomposed during plasma gasification.

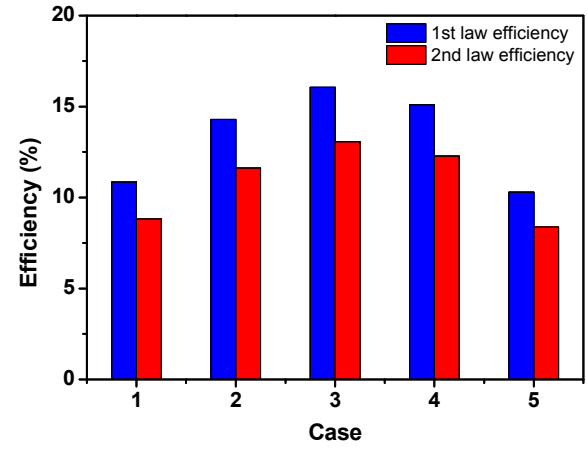

(a) Air injection gasification

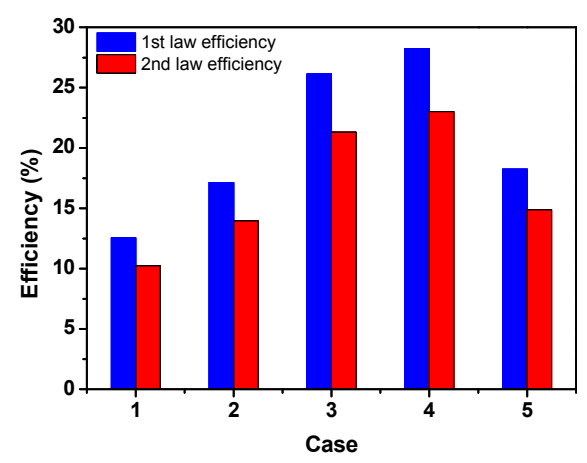

(b) Steam injection gasification

Fig. 8. The efficiency in air and steam gasification. 


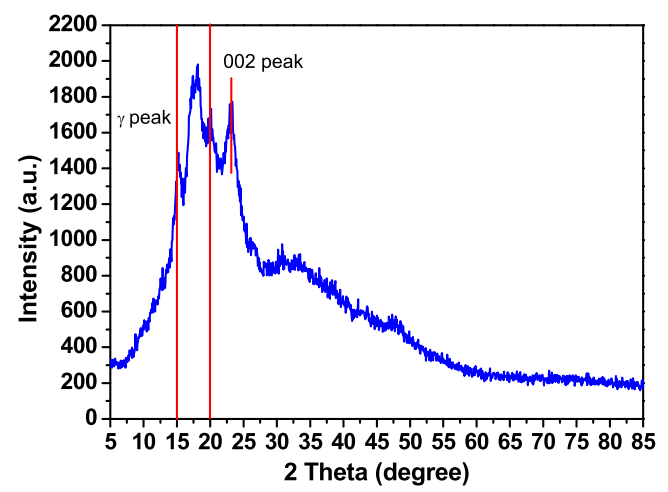

(a) Raw material

(The $\gamma$ peak almost certainly stands for aliphatic chains.

And the 002 peak is accepted as standing for the carbon microcrystalline.)

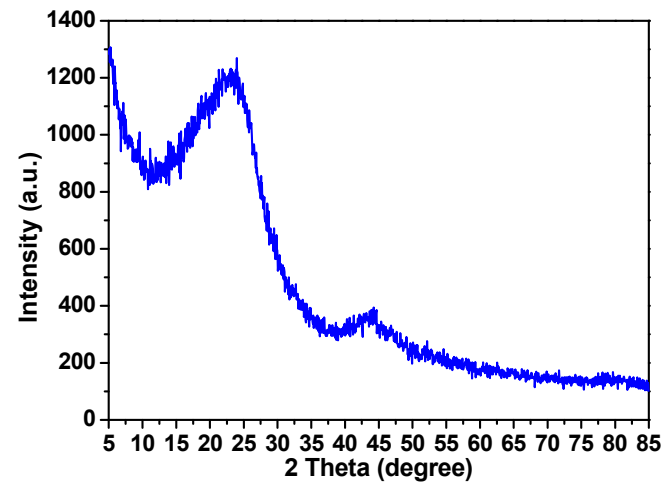

(b) Char from the plasma gasification of steam (CS)

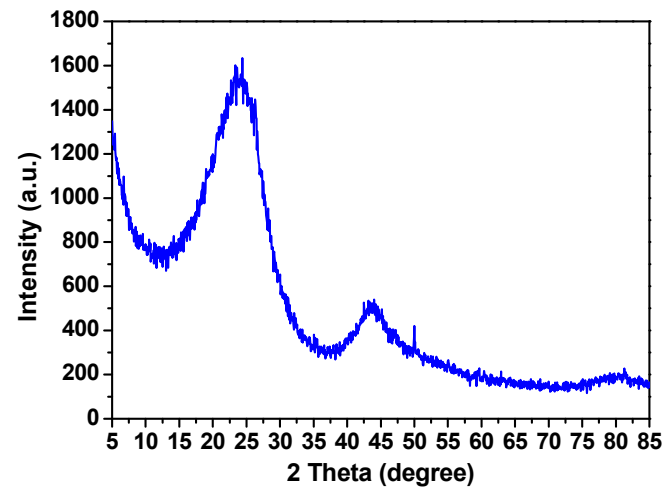

(c) Char from plasma gasification of air (CA)

Fig. 9. X-ray intensity curves.

Furthermore, it can be observed that the intensity curve of CS is lower than that of CA. The lower intensity curve of CS implies that more aliphatic groups and aromatic structure are detached from the raw material during plasma gasification of steam [29]. This is in agreement with the analysis of Reactions (3) and (4) (see Section 3.2).

In order to better understand carbon structural features during the gasification, Raman spectroscopy is the most powerful method to characterize the structural features of the residual carbons, because it is sensitive not only to the crystalline structures but also to the amorphous structures [30]. Therefore, Raman spectroscopy is employed to characterize the microstructures of the residual carbons. As shown in Fig. 8, except the G band at about $1595 \mathrm{~cm}^{-1}$ and D1 band at about $1356 \mathrm{~cm}^{-1}$, an additional band at $1125 \mathrm{~cm}^{-1}$ (D4 band, normally at $1200 \mathrm{~cm}^{-1}$ ) occurs in the CA, which also means the defects exist in carbon crystalline lattices of CA [26], leading to a downshift of 002 band of CA in XRD curve. Generally, the $G$ band corresponds to the stretching vibration mode with $E_{2 g}$ symmetry in the aromatic layers of the normal graphite structure. And the D1 band is attributed to the $\mathrm{A}_{1 \mathrm{~g}}$ vibration mode with defect structure of graphite [31,32]. The D4 band is 
Table 4

Operating parameters for SFR in the experiment.

\begin{tabular}{|c|c|c|c|c|c|}
\hline Case & 1 & 2 & 3 & 4 & 5 \\
\hline Mass flow rate of water $(\mathrm{mL} / \mathrm{min})$ & 0.20 & 0.40 & 0.60 & 0.80 & 1.10 \\
\hline Mass flow rate of steam $(\mathrm{mL} / \mathrm{min})$ & 248.89 & 497.78 & 746.67 & 995.56 & 1368.89 \\
\hline SFR & 0.021 & 0.042 & 0.063 & 0.084 & 0.116 \\
\hline
\end{tabular}

Table 5

Microstructure intensity ratio of residual carbons in CA and CS.

\begin{tabular}{lll}
\hline Sample & CA & CS \\
\hline $\mathrm{I}_{\mathrm{D}} / \mathrm{I}_{\mathrm{G}}$ & 2.02 & 3.83 \\
FWHM of D band & 331.7 & 358.3 \\
$\mathrm{I}_{2 \mathrm{D}} / \mathrm{I}_{\mathrm{G}}$ & 0.55 & 0.50 \\
\hline
\end{tabular}

associated with the mixed $\mathrm{sp} 2-\mathrm{sp} 3$ bond form at the periphery of crystallites or with $\mathrm{C}-\mathrm{C}$ and $\mathrm{C}=\mathrm{C}$ stretching vibration of polyene-like structure $[26,31,32]$.

It is generally considered that the intensity ratio of $\mathrm{I}_{\mathrm{D} 1} / \mathrm{I}_{\mathrm{G}}$ is employed to evaluate the degree of graphitization of the material. Theoretically, the ratio is smaller, the microcrystalline structures are larger, and the degree of graphitization is higher [31,32]. Table 5 illustrates the results of $\mathrm{I}_{\mathrm{D} 1} / \mathrm{I}_{\mathrm{G}}$ in Fig. 10. It is obvious to see that the $\mathrm{I}_{\mathrm{D} 1} / \mathrm{I}_{\mathrm{G}}$ of $\mathrm{CS}$ is larger than that of CA and the Full-Width Half Maximum (FWHM) of D

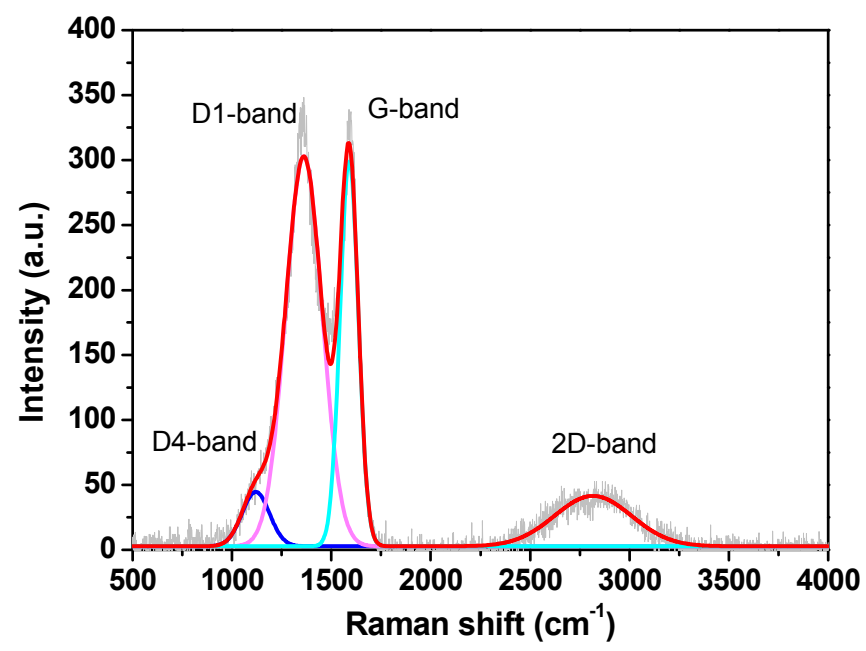

(a) Raman spectra of CA

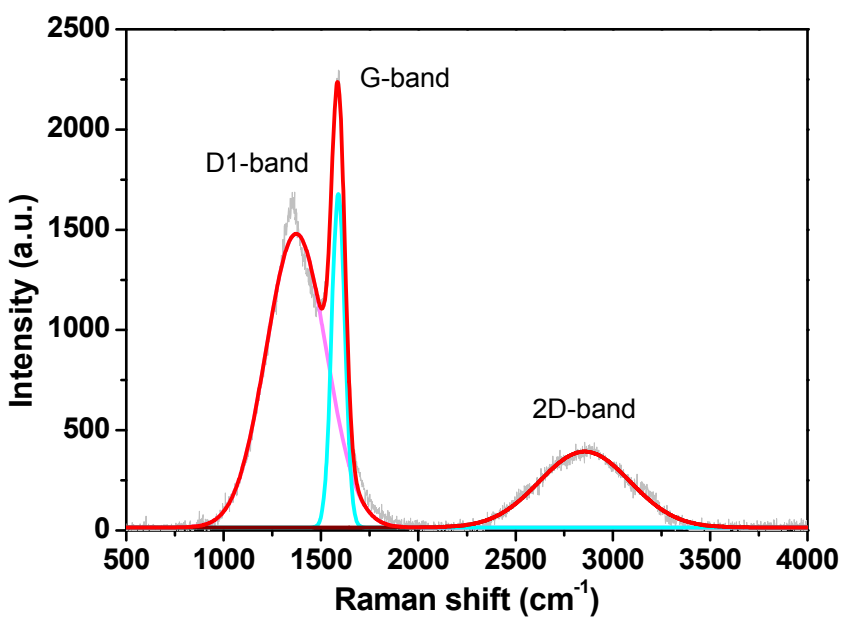

(b) Raman spectra of CS

Fig. 10. Raman spectra of CA and CS. 
band in CS is larger than that of CA. These two parameters demonstrate that the degree of graphitization in CS is lower than that of CA, thus the amorphous carbon is the main existence form during the steam gasification, which is beneficial to promoting the Reaction (3) and (4) with the free radical from $\mathrm{H}_{2} \mathrm{O}$, such as $\cdot \mathrm{H}$ and $\cdot \mathrm{OH}$. As a result, the yield of syngas during the steam gasification is higher than that of air gasification. In other words, the degree of graphitization is competing with a high yield of syngas during plasma gasification.

\section{Conclusion}

This research was devoted to investigating the main performance of plasma gasification related to kitchen waste. Experiments mainly focus on the influence of equivalence ratio (ER) and steam to feedstock ratio (SFR). The optimal experimental parameters can be obtained at $\mathrm{ER}=0.095$ and $\mathrm{SFR}=0.084$

In the air injection gasification, the ER is of two contradictory effects on syngas yields and LHV. When the ER is lower than 0.095 , chemical heat is dominant; When the ER is larger than 0.095 , the syngas is combusted. The extremely high temperature generated by the plasma torch provides a high-temperature-reaction chamber, which is apt to decompose the organic waste and combusting. As a result, the optimal ER in plasma gasification is much lower than that of conventional gasification (about ER $=0.3$ ).

Steam injection favors syngas production and efficiency, which mainly results from heterogeneous water gas shift reaction. The efficiency in the present system varies from about $7 \%$ to about $28.2 \%$. The tendency of efficiency is similar to that of the concentration of syngas. And the maximum first and second efficiency of plasma gasification during these cases occurs in SFB $=0.084$, accounting for $28.2 \%$ and $23.0 \%$, respectively, but the interface between jet and feedstock is so narrow that the horizontal experimental system has low efficiency.

The XRD and Raman spectra are employed to characterize the residual char. The presented results illustrate that most aliphatic chains are decomposed during plasma gasification. Concurrently, the results of Raman spectra may illustrate the amorphous carbon is the main existence form during the steam gasification, which is beneficial to promoting the free radical from $\mathrm{H}_{2} \mathrm{O}$, such as $\cdot \mathrm{H}$ and $\cdot \mathrm{OH}$, meaning that the degree of graphitization is competing with a high yield of syngas during plasma gasification.

\section{Acknowledgements}

This work was supported by the National Key R\&D Program of China (Grant Numbers: 2016YFB0600601) and the Strategic Priority Research Program of Chinese Academy of Sciences (Grant Number: XDA17030100).

\section{Appendix A. Supplementary data}

Supplementary data to this article can be found online at https://doi.org/10.1016/j.joei.2019.02.004.

\section{References}

[1] X. Chen, Y. Geng, T. Fujita, An overview of municipal solid waste management in China, Waste Manag. 30 (2010) 716 -724.

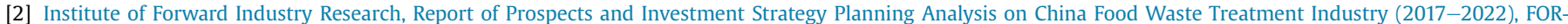
WARD Business Information Co. Ltd, Shenzhen, 2016 (in Chinese).

[3] Eurostat. http://ec.europa.eu/eurostat/data/database. (Accessed 14 November 2017).

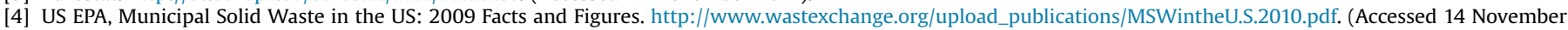
2017).

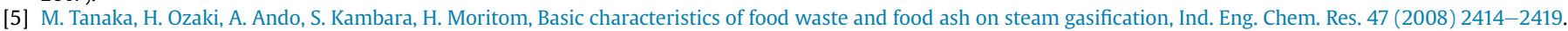

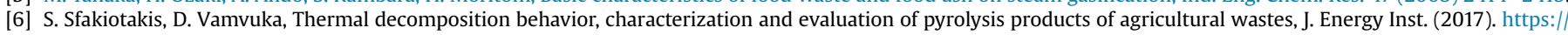
doi.org/10.1016/j.joei.2017.09.001.

[7] B.B. Uzun, E. Yaman, Pyrolysis kinetics of walnut shell and waste polyolefins using thermogravimetric analysis, J. Energy Inst. 90 (2017) 825 -837.

[8] N. Abdoulmoumine, S. Adhikari, A. Kulkarni, S. Chattanathan, A review on biomass gasification syngas cleanup, Appl. Energy 155 (2015) $294-307$.

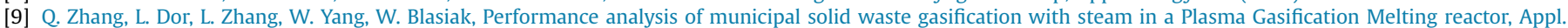
Energy 98 (2012) 219-229.

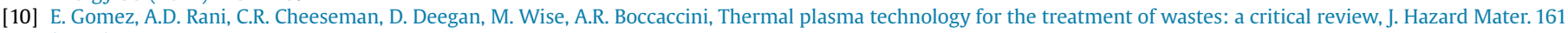
(2009) 614-626.

[11] H. Huang, L. Tang, Treatment of organic waste using thermal plasma pyrolysis technology, Energy Convers. Manag. 48 (2007) $1331-1337$.

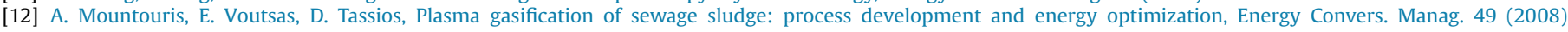
2264-2271.

[13] J. Heberlein, A.B. Murphy, Thermal plasma waste treatment, J. Phys. D Appl. Phys. 41 (2008) 053001.

[14] A. Sanlisoy, M.O. Carpinlioglu, A review on plasma gasification for solid waste disposal, Int. J. Hydrog. Energy 42 (2017) $1361-1365$.

[15] L. Tang, H. Huang, Z. Zhao, C.Z. Wu, Y. Chen, Pyrolysis of polypropylene in a nitrogen plasma reactor, Ind. Eng. Chem. Res. 42 (2003) 1145-1150.

[16] Y.J. Li, Z.Q. Huang, Y.X. Xu, H.Z. Sheng, Plasma-arc technology for the thermal treatment of chemical wastes, Environ. Eng. Sci. 26 (2009) 731-737.

[17] J.L. Zhang, Y.J. Li, G.Q. Wang, Y.X. Xu, H.Z. Sheng, Formation mechanism of vitrified slag and heavy metal fixed efficiency, Ciesc J. 62 (2011) 215-218 (in Chinese).

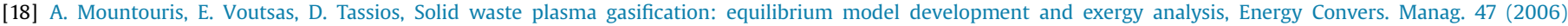
$1723-1737$.

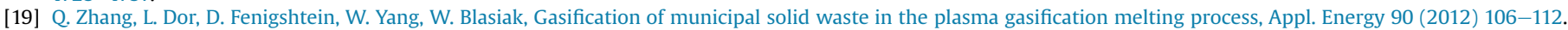

[20] J. Favas, E. Monteiro, A. Rouboa, Hydrogen production using plasma gasification with steam injection, Int. J. Hydrog. Energy 1 (2017) 1-10.

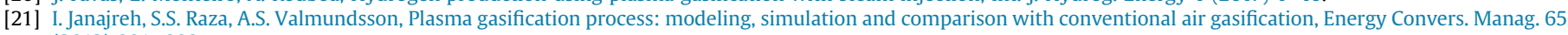
(2013) 801-809.

[22] N.J. Themelis, Y.H. Kim, M.H. Brady, Energy recovery from New York City municipal solid wastes, Waste Manag. Res. 20 (2002) $223-233$.

[23] J. Favas, E. Monteiro, A. Rouboa, Hydrogen production using plasma gasification with steam injection, Int. J. Hydrog. Energy 42 (2017) $10997-11005$.

[24] C. Li, K. Suzuki, Tar property, analysis, reforming mechanism and model for biomass gasification - an overview, Renew. Sustain. Energy Rev. 13 (2009) $594-604$.

[25] K.J. Ptasinski, M.J. Prins, A. Pierik, Exergetic evaluation of biomass gasification, Energy 32 (2007) 568-574.

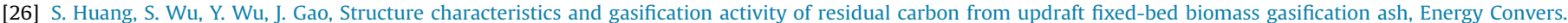
Manag. 136 (2017) 108-118.

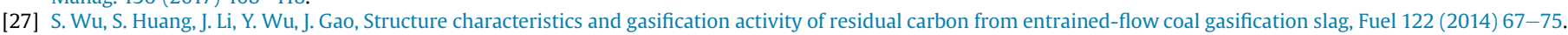

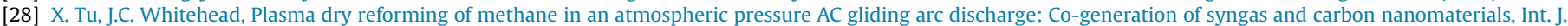
Hydrog. Energy 39 (2014) 9658-9669.

[29] G. Hu, H. Huang, Y. Li, Hydrogen-rich gas production from pyrolysis of biomass in an autogenerated steam atmosphere, Energy Fuels 23 (2009) $1748-1753$.

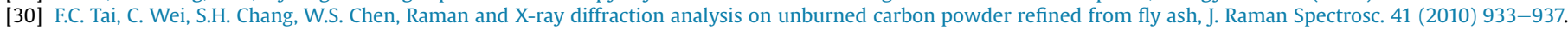




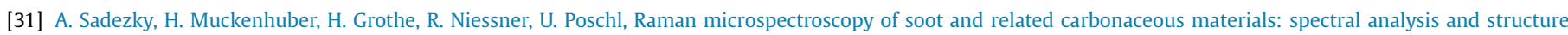
information, Carbon 43 (2005) 1731-1742.

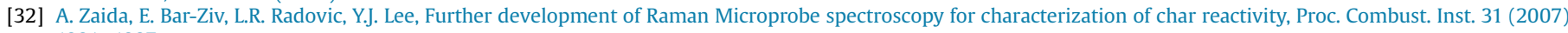
1881-1887. 